\title{
Efficiency improvement in solid-state-dye-sensitized photovoltaics with an amphiphilic Ruthenium-dye
}

\author{
Lukas Schmidt-Mende, ${ }^{\text {a) }}$ Shaik M. Zakeeruddin, and Michael Grätzel \\ Institut des Sciences et Ingénierie Chimiques (ISIC), Laboratoire de Photonique et Interfaces (LPI), \\ Ecole Polytechnique Fédérale de Lausanne (EPFL), CH-1015 Lausanne, Switzerland
}

(Received 26 July 2004; accepted 2 November 2004; published online 28 December 2004)

\begin{abstract}
We report a solid-state-dye-sensitized solar cell with an efficiency of $4 \%$ over the standard air mass 1.5 spectrum $\left(100 \mathrm{~mW} / \mathrm{cm}^{2}\right)$. This was made possible by using an amphiphilic dye with hydrophobic spacers. We

on the $\mathrm{TiO}_{2}$ surface $\mathrm{w}$

dense layer as blocking layer between hole conductor and $\mathrm{TiO}_{2}$. In addition we studied the dependence of the thickness of the nanoporous $\mathrm{TiO}_{2}$ layer and the device performance. These results show the high potential for solid-state-dye-sensitized solar cells to compete with amorphous silicon cells as low-cost alternative. (C) 2005 American Institute of Physics. [DOI: 10.1063/1.1844032]
\end{abstract}

Dye sensitized solar cells are a viable alternative for conventional solar cells. Since the first report of a highly efficient dye sensitized solar cells in $1991^{1}$ many groups have been working on this type of cell and could improve the efficiency further. ${ }^{2-4}$ Values exceeding $10 \%$ efficiency at one sun illumination have been reached. ${ }^{5}$ It is advantageous to replace the liquid electrolyte of these cells with a solid hole conductor to avoid any sealing and long-term stability problems. Since the first successful implementation of an organic hole conductor as replacement for the liquid electrolyte the efficiency has increased from $0.74 \%$ up to $3.2 \% .^{6-8}$ A key issue to get higher values is a complete wetting of the pores of the nanoporous $\mathrm{TiO}_{2}$ matrix. The devices in this letter show efficiencies of up to $4 \%$, which are attributed to the usage of an amphiphilic ruthenium dye that seems to improve the wetting of the $\mathrm{TiO}_{2}$ surface by the hole conductor.

The structure of our cells is schematically shown in Fig. 1. The cells consist of F-doped $\mathrm{SnO}_{2}$ conducting glass substrates onto which a compact $\mathrm{TiO}_{2}$ layer was deposited by spray pyrolysis. ${ }^{9}$ This is necessary to avoid direct contact between the hole conductor and the $\mathrm{SnO}_{2}$, which would short-circuit the cell. The hole conductor forms an ohmic contact to the $\mathrm{SnO}_{2}$ and charges would recombine at this interface. A dense $\mathrm{TiO}_{2}$ blocking layer impedes this current loss. The nanoporous $\mathrm{TiO}_{2}$ layers were deposited by doctorblading. This method allowed us to produce homogeneous nanoporous $\mathrm{TiO}_{2}$ films with controlled thickness. After sintering the $\mathrm{TiO}_{2}$ layer at $450{ }^{\circ} \mathrm{C}$ it was sensitized by soaking it in a $3 \times 10^{-4} \mathrm{M}$ solution of amphiphilic polypyridyl ruthenium complex, cis-RuLL'(SCN)2 ( $L=4,4^{\prime}$-dicarboxylicacid-2,2'-bipyridine, $\quad L^{\prime}=4,4^{\prime}$-dinonyl-2,2'-bipyridine) (Z907) (Fig. 1) in acetonitrile:tert.-butanol (1:1 vol \%) at room temperature. This dye contains two carboxylate groups to anchor to the $\mathrm{TiO}_{2}$ surface and hydrophobic spacer providing an insulating barrier to avoid charge carrier recombination. It has already successfully been employed in polymer gel-electrolyte cells and showed a remarkably long-term stability. ${ }^{10,11}$

As organic holeconductor we used 2,2',7,7'-tetrakis -( $N, N$-di- $p$-methoxyphenylamine $) 9,9^{\prime}$-spirobifluorene(spiro-

\footnotetext{
${ }^{a)}$ Electronic mail: lukas.schmidt-mende@epfl.ch
}

OMeTAD) (Fig. 1). We dissolved the spiro-OMeTAD in chlorobenzene and added $\mathrm{Li}\left[\mathrm{CF}_{3} \mathrm{SO}_{2}\right]_{2} \mathrm{~N}$, tert.-butylpyridine and $\mathrm{N}(\mathrm{PhBr})_{3} \mathrm{SbCl}_{6}$ and then deposited it onto the dye sensitized substrate and let it penetrate into the pores of the $\mathrm{TiO}_{2}$ layer for $1 \mathrm{~min}$ prior to spin coating. The device was finished by evaporating a $30 \mathrm{~nm}$ gold electrode on top.

A summary of previously reported values ${ }^{7}$ for spiroOMeTAD cells and our cells is shown in Table I: With the dye used in this letter we find an immensely enhanced photocurrent of $J_{S C}=8.3 \mathrm{~mA} / \mathrm{cm}^{2}$. This enhancement by almost a factor of 2, an open circuit potential of $V_{O C}=750 \mathrm{mV}$, and a fill factor of $F F=65 \%$ leads to an efficiency of $\eta=4 \%$ (Fig. 2 ). It was previously reported that a silver complexation of the dye sensitizer could improve the dye uptake and with this the efficiency of the cell sensitized with N719 as a result of an increased open circuit potential and short circuit current. ${ }^{7}$ With the Z907 dye we could observe an increase in the open circuit voltage after silver complexation, but a drop in the

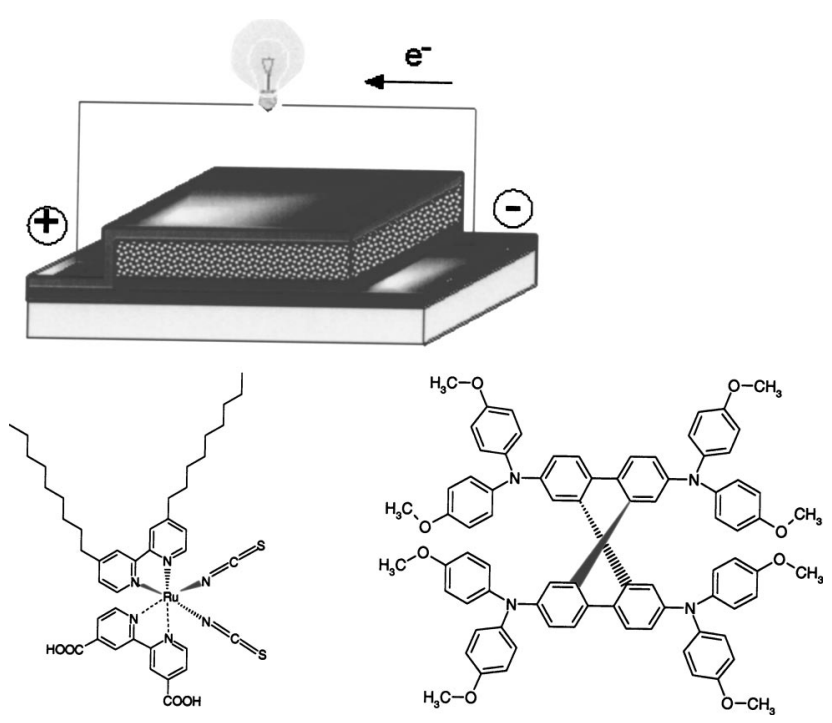

FIG. 1. The device structure consists of a glass substrate coated with F-doped $\mathrm{SnO}_{2}$. On top of this a dense layer of $\mathrm{TiO}_{2}$ is deposited by spray pyrolysis and a nanoporous $\mathrm{TiO}_{2}$ layer by doctor-blading. The nanoporous layer is soaked in dye and filled with the hole conductor. A gold electrode is evaporated on top as counter electrode. The molecular structure of the Z-907 and the Spiro-OMeTAD are shown below. 
TABLE I. Summary of the photovoltaic performance at an illumination intensity of one sun (AM1.5 global, $100 \mathrm{~mW} / \mathrm{cm}^{2}$ ). The values I and II are taken from Ref. 7. (In a control experiment we achieved very similar results to I.) Devices I and II are dyed in a $5 \times 10^{-4} \mathrm{M}$ solution of $\left(\mathrm{Bu}_{4} \mathrm{~N}\right)_{2}\left[\mathrm{Ru}(\mathrm{dcbpyH})_{2}(\mathrm{NCS})_{2}\right]$ (with $\mathrm{Bu}_{4} \mathrm{~N}=$ tetrabutyl-ammonium and dcbpyH $_{2}=2,2^{\prime}$ bipyridyl-4,4' -dicarboxylic acid) (N719) in $\mathrm{CH} 3 \mathrm{CN}: \mathrm{t}-$ butanol (1:1), for device II in addition of silver in the solution. For devices III and IV the new dye Z907 was used without and with the addition of silver in the solution, respectively. $\left(J_{S C}\right.$ : short circuit current density, $U_{O C}$ : short circuit potential, FF: fill factor and $\eta$ : conversion efficiency). The hole conductor matrix was in all cases the spiro-OMeTAD with additional $\mathrm{Li}\left(\mathrm{CF}_{3} \mathrm{SO}_{2}\right)_{2} \mathrm{~N}$, tBP and $\mathrm{N}(\mathrm{PhBr})_{3} \mathrm{SbCl}_{6}$.

\begin{tabular}{cllll}
\hline \hline Device & $J_{S C}\left(\mathrm{~mA} / \mathrm{cm}^{2}\right)$ & $U_{O C}(\mathrm{mV})$ & FF $(\%)$ & $\eta(\%)$ \\
\hline I & 3.5 & 821 & 69 & 2.1 \\
II & 4.6 & 931 & 71 & 3.2 \\
III & 8.3 & 752 & 64 & 4.0 \\
IV & 5.5 & 858 & 67 & 3.1 \\
\hline \hline
\end{tabular}

photocurrent, which leads to a decreased overall efficiency over the solar spectrum. We attribute this behavior to the already very compact packing of the $\mathrm{Z} 907$ dye on the $\mathrm{TiO}_{2}$ surface, which cannot be further improved with the silver complexation. Therefore an improved dye uptake cannot be observed. UV-Vis measurements confirmed that silver complexation of $\mathrm{Z} 907$ absorbed on $\mathrm{TiO}_{2}$ films merely resulted in an unfavorable blueshift of the dye absorption by $\sim 30 \mathrm{~nm}$, while the peak absorptivity of the dyed layer was not affected. We attribute the lower current to the blueshift in the color of the dye with the silver complexation by consistent dye uptake. Although the molar extinction coefficient of the N719 dye is stronger than that of the Z907, adsorbed on a identical 2- $\mu \mathrm{m}$-thick nanoporous $\mathrm{TiO}_{2}$ films with the hole conductor solution spin coated on top, the absorption peak of Z907 dyed film is more than 15\% higher.

The performance of our cells can be explained by a compact packing of the dye on the $\mathrm{TiO}_{2}$ surface. Due to its amphiphilic structure the dye seems to self-assemble to the $\mathrm{TiO}_{2}$ surface in a very compact layer with its hydrophobic isolating chains as dense blocking layer between hole conductor and $\mathrm{TiO}_{2}$, which effectively avoids charge recombination.

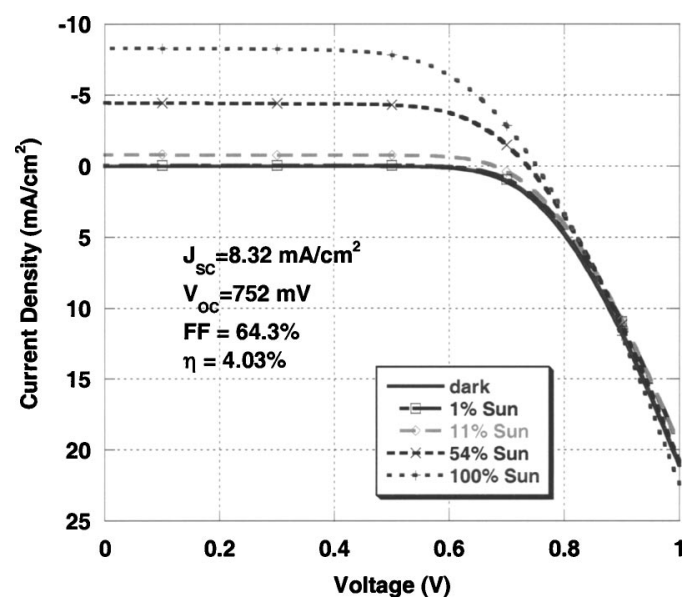

FIG. 2. Current-voltage characteristic of the device in the dark and under different light intensities up to 1 Sun. $\left(J_{S C}\right.$ : short circuit current densitiy, $V_{O C}$ : open circuit potential, FF: fill factor and $\eta$ : conversion efficiency. All numbers are given for one sun (AM 1.5 global, $100 \mathrm{~mW} / \mathrm{cm}^{2}$ ) illumination.

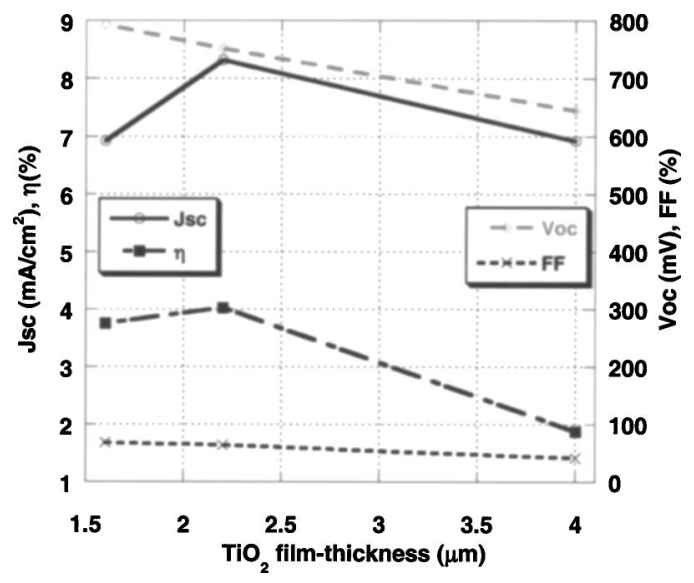

FIG. 3. Relation between film thickness (in $\mu \mathrm{m}$ ) and short circuit current density $\left(J_{S C}\right.$ in $\left.\mathrm{mA} / \mathrm{cm}^{2}\right)$, open circuit potential $\left(V_{O C}\right.$ in $\mathrm{mV}$ ), fill factor (FF in \%), and conversion efficiency ( $\eta$ in $\%$ ).

We investigated device performance subject to the thickness of the nanoporous $\mathrm{TiO}_{2}$ layer. The thickness was varied by using different spacers for doctor-blading the identical paste. It turned out that for this device type the ideal thickness is just over $2 \mu \mathrm{m}$ (Fig. 3). In thinner $\mathrm{TiO}_{2}$ layers the amount of absorbed light in the active cell area is smaller and therefore only a fraction of the sunlight can be converted. With increasing film thickness the amount of absorbed light increases, but the path for the charges to the electrodes is increasing as well, which leads to a higher series resistance and increased charge recombination in the cell and less charges that will reach the counter electrode. This trade-off between light harvesting and series resistance leads to an optimal thickness. As can be seen from Fig. 3, devices with thinner nanoporous $\mathrm{TiO}_{2}$ layers have smaller photocurrents and with thicker layers a decreased open circuit potential and a smaller fill factor. Both effects lower the overall efficiency. The lower current for thinner devices is due to a smaller fraction of light, which is absorbed in the film. Due to an increasing series resistance in the cell with increasing thickness of the $\mathrm{TiO}_{2}$ layer, more charges recombine before they reach the electrodes, which leads to the observed decreased open circuit voltage.

This work shows that the solid state dye sensitized solar cells have a great potential. An efficiency of $4 \%$ could be achieved and further improvement is expected. Our studies of the device thickness support the following assumptions: If we succeed to find a dye with a higher absorption coefficient and otherwise the same amphiphilic properties as the Z907 more light can be absorbed. The $\mathrm{TiO}_{2}$ thickness does not have to be increased in this case and therefore even higher current can be expected. On the other hand, a hole conductor with higher charge carrier mobility would allow thicker $\mathrm{TiO}_{2}$ films without increasing the series resistance of the cell. Therefore these types of cells are very promising and higher efficiencies can be expected for the future. With this prospective these cells seem to have a high potential as a cheap alternative to conventional photovoltaic devices.

The authors wish to acknowledge the supply of the spiro-OMeTAD by Covion Organic Semiconductor GmbH and the European Commission for partial funding (MOLYCELL project, contract No SES6-CT-2003-502783). L.S.M. 
thanks the German Research Foundation (DFG) for funding (Emmy-Noether Stipendium).

${ }^{1}$ B. O'Regan and M. Grätzel, Nature (London) 353, 737 (1991).

${ }^{2}$ K. Tennakone, P. K. M. Bandaranayake, P. V. V. Jayaweera, A. Konno, and G. R. A. Kumara, Physica E (Amsterdam) 14, 190 (2002).

${ }^{3}$ K. Tennakone, G. R. R. A. Kumara, I. R. M. Kottegoda, and V. P. S. Perera, Chem. Commun. (Cambridge) 1, 15 (1999).

${ }^{4}$ Z. S. Wang, C. H. Huang, Y. Y. Huang, Y. J. Hou, P. H. Xie, B. W. Zhang, and H. M. Cheng, Chem. Mater. 13, 678 (2001).

${ }^{5}$ M. Grätzel, J. Photochem. Photobiol. C 4, 145 (2003).
${ }^{6}$ U. Bach, D. Lupo, P. Comte, J. E. Moser, F. Weissörtel, J. Salbeck, H. Spreitzer, and M. Grätzel, Nature (London) 395, 583 (1998).

${ }^{7}$ J. Krüger, R. Plass, M. Grätzel, and H. J. Matthieu, Appl. Phys. Lett. 81, 367 (2002).

${ }^{8}$ J. Krüger, R. Plass, L. Cevey, M. Piccirelli, M. Grätzel, and U. Bach, Appl. Phys. Lett. 79, 2085 (2001).

${ }^{9}$ L. Kavan and M. Grätzel, Electrochim. Acta 40, 643 (1995).

${ }^{10} \mathrm{P}$. Wang, S. M. Zakeeruddin, I. Exnar, and M. Grätzel, Chem. Commun. (Cambridge) 24, 2972 (2002)

${ }^{11}$ P. Wang, S. M. Zakeeruddin, R. Humphry-Baker, J. E. Moser, and M. Grätzel, Adv. Mater. (Weinheim, Ger.) 15, 2101 (2003). 